\title{
Scale-up of a rotating packed bed reactor with mesh-pin rotor: \\ (I) hydrodynamic studies
}

\author{
Wei Liu ${ }^{\dagger, t}$, Yong Luo ${ }^{\dagger \neq},{ }^{*}$, Ya-Zhao Liu ${ }^{\dagger, *}$, Guang-Wen Chu ${ }^{\dagger, *}, *$ \\ $\dagger$ State Key Laboratory of Organic-Inorganic Composites and $\ddagger$ Research Center of the \\ Ministry of Education for High Gravity Engineering and Technology, Beijing \\ University of Chemical Technology, Beijing 100029, PR China \\ * Corresponding author. Tel: +86 10 64446466; Fax: +86 1064434784. \\ E-mail address: luoyong@mail.buct.edu.cn; chugw@mail.buct.edu.cn
}



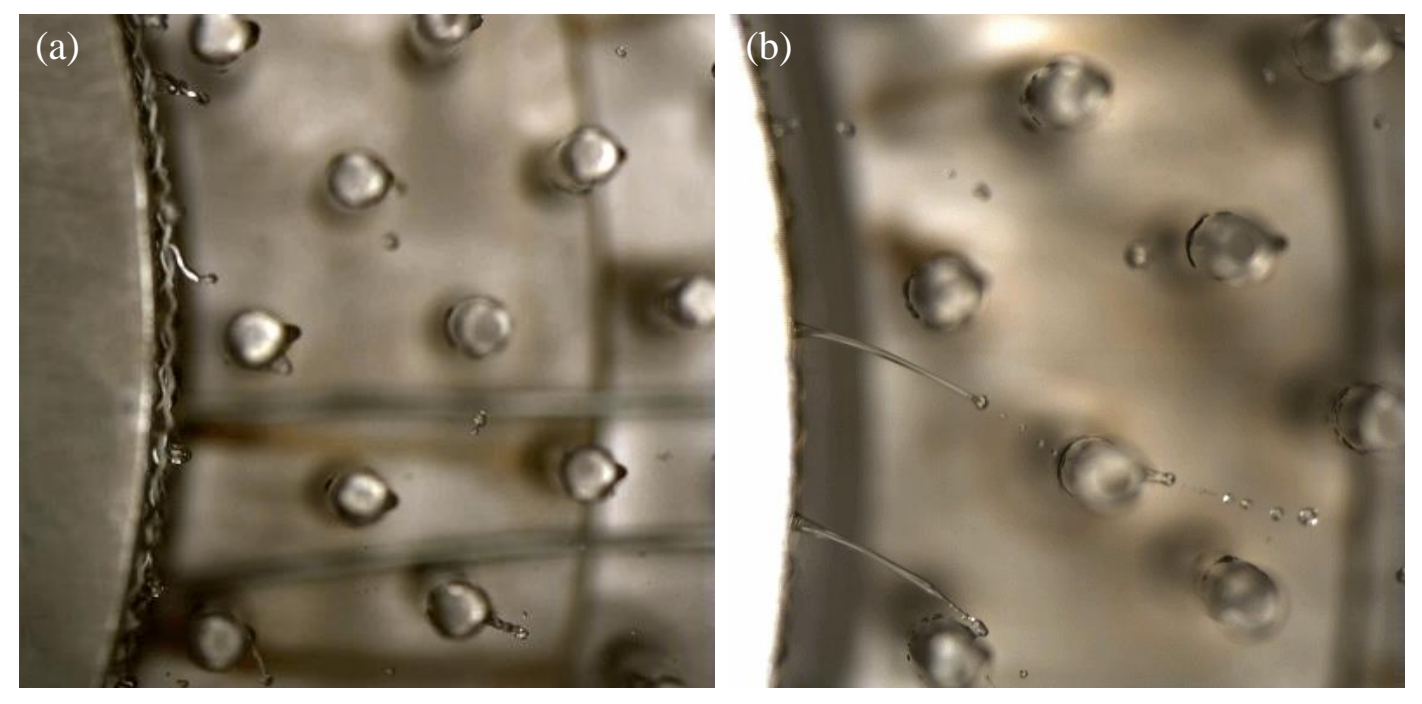

Figure S1. Liquid flow pattern in the packing peripheral edge and inside the pin zone.

(a) fiber diameter $0.45 \mathrm{~mm}$ and opening size $4 \mathrm{~mm}$; (b) fiber diameter $0.18 \mathrm{~mm}$ and opening size $1.2 \mathrm{~mm}$

The image is gif format. Please double-click the image. 

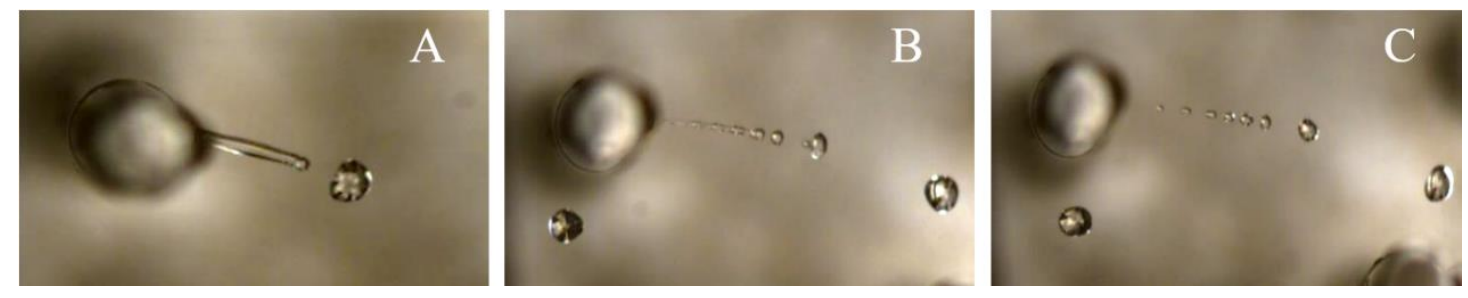

(a)
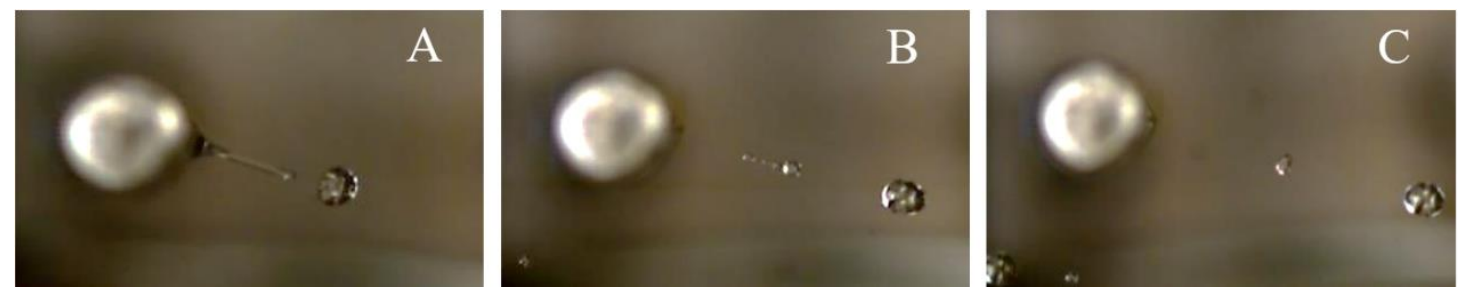

(b)

Figure S2. Liquid ligament breakup modes of water and glycerin $(N=400 \mathrm{r} / \mathrm{min})$.

(a) water; (b) $40 \mathrm{wt} \%$ glycerin 